ER_resub 0183 accepted version 2617

Raising children's self-efficacy through parental involvement in homework

Page 1 of $34 \quad$ restricted 
ER_resub 0183 accepted version 2617

Keith Williams*, Jennifer Swift, Hefin Williams, Victor Van Daal

Faculty of Education, Edge Hill University, Ormskirk, United Kingdom

*Keith Williams (corresponding author), williak@edgehill.ac.uk, 01695650866;

Jennifer Swift, swiftj@edgehill.ac.uk; Hefin Williams, williamh@edgegill.ac.uk; Victor Van Daal, victor.vandaal@edgehill.ac.uk

Keith Williams is Senior Lecturer in Professional Education. Jennie Swift and Hefin Williams are both Senior Lecturers in Early Years Education. Victor van Daal is Professor of Education in the Faculty of Education. 


\title{
Raising children's self-efficacy through parental involvement in homework
}

\begin{abstract}
Background This paper is a qualitative evaluation of a small-scale pilot study that attempted to generate parental involvement in children's learning. It used problem solving mathematics homework in order to raise the children's self-efficacy, or, put another way, the child's belief that success lies in their own hands.

Purpose Homework is often seen as a common sense practice which is conducive to the development of the attributes of an effective learner. The pilot investigated whether situating homework tasks in everyday mathematical contexts enhanced parent-child interaction. If so, the child was then more likely to commit to learning, recognise the usefulness of mathematics as a life skill, and the value of sharing ideas and accepting feedback.

Design and methods The pilot took place between April and July 2015 in a primary school in the Northwest of England. Participants were a class of nine and ten year old children $(n=27)$, their two class teachers and a self-selecting sample of parents. Children were asked to work on open-ended problem-solving activities designed to connect with everyday use of mathematics. The parental role was to model, encourage and reinforce rather than instruct. Data was collected from focus groups, from parent feedback sheets and from a self-efficacy questionnaire. The data was analysed thematically.

Findings and conclusions Despite limitations of time and scale, evaluation of the pilot suggests that the homework strategy does justify further research. The qualitative analysis of the data indicates that greater involvement of parents in learning was generated, the homework was well received by children and self-efficacy levels remained stable. The next step should be to run an extended version of the pilot.
\end{abstract}

Keywords: mathematics; homework; parental involvement; self-efficacy. 


\section{Introduction}

This paper is an evaluative report of a small scale, qualitative pilot study conducted with a single class of nine and ten year old children in an English primary school. The pilot examined the feasibility of using a homework strategy to increase parental involvement in children's learning and, as a result, raise the children's self-efficacy for mathematics. Self-efficacy, or the belief that success lies in a person's own hands, is one of the attributes of an effective learner and has a bearing on children's attainment.

Homework was chosen because it is often seen by schools and parents as a common sense practice. Mathematics was chosen because of its elevated position in the curriculum hierarchy. The pilot used problem solving homework tasks constructed to reflect the families' everyday use of mathematics or children's interests. Parents were asked to use encouragement, reinforcement and modelling rather than instructional techniques to avoid reliance on parents' mathematical competence.

Underachievement in mathematics by children and young people in England remains a concern for educationalists. In 2012, the Programme for International Student Assessment (PISA) ranked the UK $26^{\text {th }}$ of 65 nations for mathematics attainment, despite the UK government spending an above average proportion of Gross Domestic Product on education (OECD, 2012). In 2015, 31\% of GCSE entrants in England failed to achieve grades $\mathrm{C}$ or above, which is the benchmark for employers and for Higher Education institutions (gov.uk, 2016).

Educationalists continue to try and identify strategies to address this problem. One strategy that has proved to be productive is increasing parental involvement in children's learning (DfE, 2015; Van Voorhis, 2009; 2011; Wilder, 2014). Harris and Goodall assert that it is when parents get involved in their children's learning at home that they make the greatest difference to student achievement (Harris and Goodall, 2008, p. 277). In England, the Office for Standards in Education (Ofsted), the national inspection body for all maintained schools, recently produced a revised inspection framework for schools (Ofsted, 2015), which states that in order to achieve an "outstanding" grade, schools must demonstrate how they engage with the parents or carers of all children to improve their learning. The framework also recognises the 
setting of "appropriate" and "challenging" homework (Ofsted, 2015, p. 48). This focus is not limited to England, however: in the United States, Kraft and Rogers' (2015, p. 49) claim that the government has cited increased parental support as a "top priority" for improving achievement.

The combination of research evidence and government priorities therefore make parental involvement in homework a logical strand of inquiry. The pilot study went beyond the "common sense" conception of homework as more time on task to review, practice and complete. Rather, it set out to use a different type of homework with two main questions in mind: Can homework be used to generate greater parental involvement in children's learning? Does parental use of strategies to support learning during homework increase children's self-efficacy level in mathematics?

The design of the homework drew on previous research from the United States and United Kingdom. In the UK, Ocean Mathematics (Bernie and Lall 2008) and IMPACT mathematics (Mertens and Vass, 1993) focused on interactive game playing and procedural work to raise attainment. In the USA, the 'Teachers Involve Parents in Schoolwork' (TIPS) programme focused on the concepts and skills included in district school tests using homework projects that required interaction, discussion and experimentation alongside a family member (Van Voorhis, 2009, p. 143; 2011). Aspects of all three were considered during the design of the pilot.

Homework packs were sent home every week over a period of eight weeks and three sets of data were collected: parent feedback sheets, pupil self-efficacy questionnaires and focus groups with pupils and parents. The results were promising. Greater involvement of parents in learning was generated, the homework was well received and self-efficacy levels remained stable. The remainder of this paper outlines the theoretical rationale on which the pilot was designed and the responses of participants to the pilot, in order to ascertain the feasibility of further experimentation.

\section{Theoretical rationale}


The pilot was developed using research evidence that addressed the following questions:

- what is the rationale for involving parents in mathematics homework?

- is there a specific form of parental involvement that is more productive than others?

A synthesis of the evidence led to the following hypothesis.

Parents hold high aspirations for their children and, if homework tasks are situated in everyday applications of mathematics problem solving skills, it enhances the likelihood that they will draw on their own experience and interact with their child. Their child is then more likely to commit to learning, recognise the usefulness of maths as a life skill, and the value of sharing ideas and accepting feedback from significant others.

The literature has been organised into connecting themes. The case for homework, its contribution to learning and the benefits of parental involvement is outlined before the implications for the pilot's design are discussed.

\section{The rationale for homework}

Homework is defined as any task assigned by teachers for pupils to be carried out during non-instructional time (Benbenutty, 2011). It is a practice that generates more parental involvement than any other. Educational policy expectations aside, homework has instructional and communicative purposes. Homework can facilitate practice, preparation and development as an independent learner. It can provide opportunities for parents and children to work together and allow parents to gain an understanding of what children are learning in school (Epstein and Van Voorhis, 2012, p. 268; Cooper et al, 2006, p. 150; DCFS, 2007).

During the completion of homework, children participate in academic and social communities [of practice] where the resources and self-efficacy of their parents come into play (Landers, 2013, p. 375). Thus, Landers claims that the degree to which children take ownership of their homework is explained by "their ability, facility, and legitimacy to contribute to, take responsibility for, and shape the meanings that matter 
in a social context" (Wenger, 1998 p. 197, cited in Landers, 2014, p. 375). So, the meaning the child gives to homework shapes the interactions they have about homework with teachers and parents. Children have a mathematical identity that is dynamic and relational and at a given point will shape their responses and potential to respond to homework (ibid. p. 376). Homework planning should, therefore, recognise the complexity of the social processes involved.

\section{Homework and its contribution to learning}

Fairly recent meta-analyses of empirical research on the relationship between homework and attainment have proved inconclusive for the primary age phase (Cooper et al 2006; Patall et al, 2008; Hattie, 2009). Hattie found an effect size of only 0.15 for homework in the primary phase, making it appear relatively insignificant. However, he also found that the nature of the homework tasks set, and the curriculum area, were influential (Hattie, 2009, p. 236). By applying what Hattie referred to as "intelligent problem solving" ( ), particular forms of homework may produce other benefits.

Both Patall et al and Epstein and Van Voorhis identified benefits related to psychological constructs such as self-efficacy and self-regulation. (Patall et al, 2008, p. 2041; Epstein and Van Voorhis, 2012, p. 265). Both studies assume that the impact parental modelling can have on self-efficacy will produce higher levels of attainment as a far transfer. The rationale for increasing children's self-efficacy through parental involvement in learning draws on Bandura's social cognitive learning theory (1997). Bandura believed that "children who display more curiosity and exploratory activities promote parental responsiveness" (ibid. p. 86). If a parent engages in varied mastery activities with their child, the child will have a greater degree of self-efficacy.

Self-efficacy can be defined as an "individual's confidence in their ability to organize and execute a given course of action to solve a problem or accomplish a task" (Eccles and Wigfield, 2002, p. 110). The strength of self-efficacy is domain-specific and it acts as a "major determinant of goal setting, activity choice, willingness to expend effort, and persistence" (ibid.). As Epstein and Van Voorhis point out (2012, p. 265 ) it is in a school's best interests to nurture learners who possess both the "cognitive 
skill and the motivational will" to become effective learners. If students believe they are capable, they are more likely to persist with homework tasks. Self-efficacy is thus an intrinsically valuable component of a child's learner identity.

\section{Parental involvement in their children's learning}

For many parents, involvement in their children's learning in the home is a naturally occurring practice. As Walker et al point out "parents choose to become involved in homework because they believe they should be involved, that their involvement will make a difference and is welcomed by schools" (Walker et al, 2004, p. 1). The idea of parental involvement as a positive influence on students' academic attainment is "so intuitively appealing" that it has been cited as "an important ingredient for the remedy for many problems in education" (Corno et al, 2001, p. 1). However, Wilder claims that a lack of clarity of definition for parental involvement is problematic for research into its effectiveness (Wilder, 2014, p. 378).

Hoover-Dempsey's hierarchy of parental involvement types offers a useful classification system (2005). At the top of the hierarchy are a number of strategies that parents could use to support their children's learning. For example, these might be interactive processes supporting children's understanding of homework, modelling or demonstration of appropriate learning processes and discussion of problem-solving strategies.

According to Epstein and Van Voorhis, when children complete appropriately designed homework they strengthen personal attitudes about learning that contribute to success in school (2012, p. 265). For example, they are more likely to manage tasks well, limit distractions and increase their motivation to learn (ibid.).

Involving parents in mathematics homework should therefore have some payoff. Corno et al found that "parental aspiration and expectation for educational achievement had a significantly stronger relationship with academic achievement than parents' supervision of children at home" (2001, cited in Wilder, 2014, p. 381). In other words, the messages parents give to their child about how they expect them to do at 
school influences their child's success - and, presumably, in their child's engagement with homework, too.

\section{Implications for mathematics homework designed to involve parents}

If the involvement of parents in children's learning is potentially powerful, the form of parental involvement also appears to be important. Kraft and Rogers argued that where messages from school were 'actionable' by the parents, they held the potential to impact on the child's trajectory, including parental involvement in homework (Kraft and Rogers, 2015, p. 50).

Silinskas et al $(2015,420)$ remind us that achieving parental involvement is not without challenge, since homework can be an "emotionally charged event" for all concerned. Engaging in homework can produce a range of emotional responses and parents need to be aware of "the dangers of the potentially vicious circle of increased negative emotion [and the] detrimental effect of over involvement" (Silinskas, 2015, p. 431). The type of parental affect is, therefore, significant. Positive affect, defined as the "enjoyable, loving, and supportive interaction" that parents can experience in homework situations can enhance the child's "feelings of relatedness and thereby promote their learning motivation" (Silinskas, 2015, p. 420).

The nature of parent-child discussion has been highlighted by several studies. Hoover-Dempsey and Sandler found that "parent-reported invitations to involvement from the child were the strongest predictor of both [child] and parent-reported homebased parental involvement" (2005, p. 357). This has implications for homework design, as does Bailey's finding that homework could encourage deep thinking and rich discussions (2006, p. 161). Sheldon and Epstein's study found homework that required children to discuss mathematics skills with a family member was seen to be effective by schools (Sheldon and Epstein, 2005, p. 204).

If homework is child-led but designed to involve the parent in the learning process, it can reduce tensions provided the parental role is to encourage, praise and model. It can help the parent to see their child as an autonomous learner. However, the 
degree to which this is achieved is influenced by a parent's interpretation of their child's level of attainment. This makes children who are struggling less likely to receive 'autonomy support' (discussion, suggestions and encouragement) (Silinskas, 2015, p. 431). The design of homework tasks and the guidance given to the child and parent offers at least a partial solution to controlling or 'surveillance' behaviour from parents. It can establish a sense of relatedness between the child and the parent and supports the child in experiencing themselves as purposeful, by communicating that they are engaged in meaningful activities (Cooper et al, 2006).

O’Sullivan et al (2014) found that autonomy support was less prevalent in low income families as a result of parents having less confidence dealing with academic content and preferring to focus on structuring the homework environment (ibid. p. 179). Drawing attention to the way that using mathematics skills is an everyday occurrence may perhaps convince parents that they can engage in discussions concerned with mathematical decision making.

The challenge of parental involvement is, however, compounded for mathematics. Parental recollections of school mathematics are not always positive. Parents communicate their beliefs and attitudes to their children and there is a considerable body of evidence which suggests that feelings of inadequacy, alienation and anxiety towards mathematics are not uncommon (Haylock, 2007; McNamara et al., 2000; Onslow, 1994). When children become anxious, it takes up some of their working memory. The danger is that some children go "under the radar" while their self-efficacy is gradually diminished (Maloney and Beilock, 2012, p. 116). However, the relationship between mathematics anxiety and self-efficacy is not fixed. Interventions that protect children from mathematics anxiety are more likely to be productive where they focus on experiences beyond the classroom (Eden et al, 2013; Maloney et al, 2012, p. 116).

Focusing on families' everyday experiences of using mathematics is significant. The ability to apply mathematical knowledge has been consistently recognised as the most challenging aspect of the mathematics curriculum to develop inside a classroom (Ofsted, 2008, 2012). If the mathematical contexts employed are familiar, it is more likely to allay parental anxiety and harness the high aspirations they have for their 
children. Nicol and Crespo (2005) indicated that imaginative tasks that have some reality connected to them are effective at engaging children. Common practice related to the homework process often takes the form of teacher demonstration of the skill followed by consolidation and application at home. However, Linsell et al (2013) suggest that procedural knowledge results from the focus on structural knowledge and does not need to be a precursor to structural knowledge. This approach emphasises the context, given at the point of entry, rather than the application of the skill at exit (Treffers and Beishuizen, 1999).

Carefully crafted homework tasks require more effort and commitment from teachers, at least until a bank of activities is developed. They should not increase the time spent on homework by children. As Van Voorhis puts it, 'better is better' (Van Voorhis, 2011, p. 333). Van Voorhis' summary encapsulates the key message from the literature reviewed:

homework can foster positive communications when its content has been well explained in class, when students and parents understand their roles in the process, and when teachers assign consistent but reasonable amounts of interesting homework that promotes and inspires learning

(ibid., p. 334).

However, Farrell and Danby offer a cautionary note. If parents see homework as compliance under the rhetoric of partnership, then the notion of developing a particular form of involvement is unlikely to succeed (2013, p. 2). Parental involvement in homework should always be part of a broader strategy to build a partnership between home and school.

\section{Methodology and Design}

As an interpretive evaluation, the pilot was epistemologically positioned by the principles of constructivism. This meant that the experiences of the participants and their responses to the pilot would be guided by the "social construction of meaning" (Greene, 2006, p. 94). Analysis of their experiences was unlikely to provide what 
Bassey (2001, p. 5) refers to as a 'guide for professional action' - rather, conducting an evaluation would reveal illuminating insights about the pilot.

The choice of methods in a study significantly determines what is learned in the evaluation (Greene, 2015, p. 748). It was essential that methods of data collection captured whether the new homework practice was appropriate and acceptable to all participants and that, where necessary, improvements to the coherence of processes were identified. Initial thoughts were that a mixed method design would suit an evaluation of the pilot, because of the twin focus on parental involvement and selfefficacy. Green advocates mixed methods because no one method can capture the "immense complexity that constitutes the meaningfulness and the effectiveness of [an] educational intervention" (Greene, 2015, p. 748). However, following theoretical and methodological deliberation, including consideration of the study's scope, the researchers opted for a qualitative approach. Inductive analysis of participant responses was used alongside a self-efficacy questionnaire, but data from the questionnaires were not used for analysis because there was no random assignment of treatment or control and no pre or post-tests of attainment were used.

In theory, any future study could be adapted to fit the principles of a mixed method design with "expansion” intent (Greene, 1989, p. 260). A qualitative methodology does not preclude the addition of quantitative methods. If the evaluation of the pilot was positive, a more complex, multipurpose design could be developed. Qualitative methods could be used to assess the efficacy of processes designed to generate parental involvement, and, a quantitative measure used to consider the outcome i.e. the effect on self-efficacy.

\section{Procedure for pilot study}

The pilot was conducted over eight weeks between April and July 2015. The participants were a full class $(n=27)$ of Year Five pupils $(9-10$ years old $)$, their parents or carers and the two teachers who shared teaching responsibility. The term 'parent' was taken to mean the adults who had care of the child and included other family members. This was important because it could be a grandmother or an older sibling who were involved in the homework. The setting was a medium sized English primary school in the northwest of England. The school was engaged through the researchers' 
professional network and was seeking to develop a closer relationship with parents. All homework tasks were designed and prepared by the researchers, following a discussion with the teachers on any current shared interests the children had. The The eight tasks covered different areas of mathematics, including money, co-ordinates, time and ratio. The tasks were contextualised. For example, one of the money-related tasks was called 'Party Bags' and involved working out the cost of providing presents for party guests; one of the tasks focussing on time was based on a scenario of making toast.

The pilot had two key features. The first was a 30 minute homework changeover session. During this session, the children shared their homework scrap books and discussed their strategies with each other and with the teachers and teaching assistant. The teachers shared examples of children's responses and celebrated their efforts. During the final ten minutes the teacher introduced the next homework task and distributed materials. Each homework task contained the following elements:

1) An introductory message to parents reminding them of the purpose of the homework;

2) Mathematics objective;

3) Materials required listed;

4) Parental feedback sheet (for activities 4-8).

The first three homework tasks were distributed to the whole class as part of their normal homework routine, with the addition of the 30 minute changeover session and a letter to parents explaining that the mathematics homework for the summer term would be a series of problem solving activities. The self-efficacy questionnaire was administered in week one and a second time prior to the fourth homework activity to see if any potential covariates (for example, the homework scrapbooks and folders and glue stick supplied to the children for recording their responses) had had an effect.

The second key feature was the parental information session held prior to the fourth homework changeover. The session was held at $9 \mathrm{am}$ and repeated at $3.30 \mathrm{pm}$ and $5.30 \mathrm{pm}$. Additional 'drop-in' sessions were offered each week to maximise face-to-face engagement. At this meeting a rationale for the pilot was given and the parental contribution explained. Parents were given information on behaviours to model, encourage and reinforce: curiosity, persistence, flexibility i.e. ability to adapt their 
approach, engagement i.e. investment and involvement in the homework, openness i.e. willingness to try new and novel approaches, responsibility i.e. taking ownership of their homework, and creativity. Kaiser and Hancock's work offered further suggestions:

- Parent engages in child's activity and balances turns with the child

- Parent responds quickly to child in a warm and positive manner

- Parent responds to content of child talk and is often at child's eye level

- Parent seeks clarification when child meanings are not understood

- Parent responds to child interpreting and expanding on their ideas

- Parent talks about what child is doing and provides positive feedback

(From Kaiser and Hancock, 2003, p.10).

Parental and pupil focus groups were held at the conclusion of the pilot in addition to data gathered from parental homework feedback sheets. The parent feedback sheet was a checklist of the behaviours/actions outlined above. In the focus groups, parents were questioned about the homework and their involvement in it and pupils were questioned on their self-efficacy, the homework and interactions with parents, using a card sort activity. The pupils were grouped for the focus groups according to the level of parental involvement. Three pupils were absent.

Group 1 - Children whose parents attended initial information session (8 children) Group 2 - Children whose parents didn't attend information session but provided feedback via the feedback sheets ( 8 children)

Group 3 - Children whose parents did not attend information session or provide feedback ( 8 children)

The focus groups investigated the children's experience of the pilot and the potential influence of factors such as the homework activities, the changeover session and the contrast with prior use of homework. As Eccles and Wigfield point out, it is difficult to understand "students' motivation and behaviours without understanding the contexts they are experiencing" (2002, p. 128). 
A self-efficacy questionnaire was used to test the feasibility of measuring selfefficacy in this context. The questionnaire was a nine item scale adapted from the Motivated Strategies for Learning Questionnaire (MSLQ) (Pintrich and De Groot, 1990). Items were adjusted for domain and context specificity and three measures were taken for internal validity (Linnenbrink and Pintrich, 2002, p. 316). The nine questionnaire items were statements written in the first person $(I)$ that expressed an opinion or attitude about mathematics from the point of view of a child. For example, one item stated 'Compared with others in my class, I think I'm good at maths'; another read 'I think I will receive good marks in maths work'. Children rated themselves on the following questions using a four point Likert-like rating scale from "not true" to "always true".

\section{Ethical considerations}

The pilot sought to influence an aspect of the relationship between home and school and was approached with great sensitivity. In seeking to adopt an appropriate ethical code the application made to the university ethics committee in January 2015 complied with BERA guidelines (2011) and upheld articles 3 and 12 of the United Nations Convention on the Rights of the Child (1990). Once approval was granted, the school was approached.

During an initial meeting at the school, an outline of the pilot was presented to the interested class teachers. Written agreement to participate was then secured from the Headteacher. As active participants, the teachers, parents and pupils were fully informed regarding the purpose and potential benefits of the pilot. A letter was sent to all parents prior to the parent information session detailing the parental role. Clear information was provided regarding the intended use of data and where it was to be disseminated. All participants were assured that their anonymity in the public domain would be protected; for example, by the use of pseudonyms. Parents were asked to contact the school if they did not wish to participate. If consent was refused, parent feedback sheets would not be sent home with the homework and the child would not be asked to complete the measurement tool or participate in a focus group. One hundred per cent participation was secured. 
After the parent session had taken place, a verbal protocol was delivered to the children, which outlined their role.

The children were asked if they would fill in a short questionnaire to help the researchers understand how confident they are when they do maths. It was made clear that they did not have to do so and that their answers would be treated with confidentiality. The risk to pupils from participation was assessed to be negligible, since increasing self-efficacy can be taken as an intrinsic "good", and parental involvement is likely to have long term benefits to learners. The homework tasks did not introduce additional burden to the children or teachers, since they were not additional to the normal homework routine and all materials were prepared by the researchers.

\section{Data Analysis}

The findings presented are based on the data elicited from the focus groups and from the parent feedback sheets collected each week. Data were transcribed and shared between the researchers to increase the reliability and consistency of the interpretations made. Familiarisation identified initial codes, then 'candidate themes' were generated using a process of reflection and interpretation to validate the context of the coding (Braun and Clarke, 2006). Further searching and reviewing refined themes prior to final reporting. The data were used to portray experiences within their natural setting and to describe and interpret what happened, in order to inform thinking on the way homework is experienced (Bassey, 1999; Stake, 1995).

Hoover-Dempsey and Sandler's model of parental involvement was used to identify significance in the data (Hoover-Dempsey and Sandler, 1995; 2005; Walker et al 2005). The model's structure may be summarised as follows. The first two levels of the model represent the decisions of parents to become involved in their child's education and the forms this involvement takes. Level three includes the mechanisms of involvement, including modelling and reinforcement. The homework was designed to stimulate these mechanisms to impact on the fourth level of the model: shared expectations between parents and teachers regarding progress and attitude. The distal relationship between self-efficacy and attainment was not the focus of the pilot. 
Figure 1. The Hoover-Dempsey \& Sandler model of parental involvement. Adapted from Hoover-Dempsey \& Sandler, 1997; 2005. Reprinted with permission from Joan Walker on behalf of the Family School Partnership Lab, Vanderbilt University.

\section{Evaluative discussion of processes and outcomes}

Analysis of the data identified two significant themes. First, anoteworthy degree of the anticipated types of parental involvement occurred. It was not only parents who were involved: six children identified a grandparent and two identified the involvement of an older sister. Second, a large proportion of the children said that they completed the homework because they enjoyed it. Clearly, a number of explanatory factors relating to specific processes within the pilot may account for these outcomes and are discussed below, in order to evaluate its feasibility. Where differences between focus groups exist, they are noted. However, the small numbers in the groups must be kept in mind: it is not the intention of this exploratory pilot study to make generalised inferences. Within this framework, the two themes are presented below, with illustrative examples from the data.

\section{Theme 1: The homework generated parental involvement}

Two factors highlighted by the data seem to give insight into why parental involvement occurred. First, parents responded positively to the information sessions and written guidance provided. They acknowledged the contribution that modelling, encouragement and reinforcement could make to their child's mathematical self -efficacy and problem solving competence. Second, the design of the homework tasks appealed to parents. They recognised the logic in using scenarios that reflected the everyday use of mathematics. Evidence is presented below to illustrate the type of interactions that took place followed by a discussion of the two explanatory factors.

\section{Parent - Child interactions}

In the pupil focus groups, a set of 10 cards was given to each participant. The statements were intended to elicit information on whether parental involvement 
happened and who initiated it. The children were asked to identify those pertinent to their experience.

The most popular statements were "If I got stuck someone was able to help me", "I told someone I was going to do my homework" and "I showed my homework to someone when it was finished". The popularity of these statements suggests that sometimes it was the children who instigated parental involvement.

The statements "someone else showed me what to do" and "someone asked me questions about my homework" refer to parents initiating involvement. These cards were popular with group one children but not the other groups. The least popular statement was "I was encouraged to complete my homework over a few days". The nature of the tasks allowed them to be spread over a longer period of time however it appears that either the children, parents or both still felt homework should be completed in a designated time slot.

The children in groups one and two identified using more strategies than those in group three. Two statements proved to be exceptions. The first, "I wanted to do more or change the task", may have been due to the children's need to adapt the task to fit their own understanding, if support was not available. The second, "I listened to someone else's suggestions", seems to be contradictory given the membership of the group. It may reflect children's awareness that listening to others is what you are meant to do. The statement "I did my homework without anyone asking me to" was popular with all three groups and might, given the age of the children, reflect the development of a homework routine.

\section{Stimulating parental involvement through an information session}

By the end of the pilot, two thirds of parents had been engaged face-to-face or provided written feedback, although only one third attended the initial information session. It was clear that some who did had to be convinced that their own degree of mathematical competence would not be exposed. The stimulation of parental involvement at the parent information sessions is, therefore, the 'high stakes' element of the pilot's design. 
This was anticipated and the term 'information session' was used, rather than the term 'workshop', to try to encourage parents who might otherwise be reluctant to attend. It is possible that mathematics anxiety may have presented a barrier for some parents. In addition, parents may have different views on the respective responsibilities of parents and teachers and the pilot may have blurred the boundary for some.

Parents liked the idea of supporting their child on tasks which used familiar mathematical contexts and acknowledged the role mathematics plays in everyday life. One parent pointed out that 'the kids don't realise and we don't realise you use maths for everything". Another parent was able to extend learning by drawing on skills used during employment, such as the use of electronic spreadsheets. This parent also reminded the researchers of the importance of recognising parental contribution when new practices are introduced, pointing out that "sometimes the parents need a pat on the back too".

The importance of homework design

The open ended nature of the tasks enabled parents to engage their children in meaningful discussion and draw on personal experiences. This prompted parental views on how children were likely to respond:

This was a different type of homework. You can set it out in different ways and it's not just on paper.

Rather than getting everyone on the same road you left it open at times.

If a parent feels they are being asked to take the role of teacher, their involvement can have a negative effect on the child (Silinskas, 2015; Van Voorhis, 2011). This meant providing clear instructions and information regarding the mathematical content of tasks. Parents highlighted how important this was. When tasks are embedded in recognisable contexts, the mathematical concepts involved may not be obvious. This was the case for the activity called Making Toast, where the mathematical content was algebraic understanding (pattern). Consequently, the comments on the feedback sheets were more negative than for previous tasks: 
Ifound this very difficult to explain and had to ask the teacher.

It was a battle to get her to communicate the task and she became upset.

He sat and listened but was unsure.

I could not seem to explain the task.

Despite this, the completion rate for the task was high, suggesting that even though they had been faced with a challenge, parents were still involved. The data reinforces the importance of sharing clear information with parents. Of the 11 children who failed to complete this task, nine came from the group with no identified parental involvement. One parent's pragmatic observation on the homework in general was that "some kids won't do anything. Some kids will do a lot".

Comments on feedback sheets indicated that parents were employing the strategies from level three of the Hoover-Dempsey and Sandler model, as advised, during the homework information sessions. Parents stated that they had made suggestions, given encouragement and offered praise:

By actually bringing our breakfast and morning into the situation (older sister during the 'Making Toast' algebraic patterns task)

By encouraging her to complete the task herself and telling her what a great job she was doing (Mother during the 'Party Bags' money problem task).

By telling her that our ideas were good (Grandmother referring to 'Friday night takeaway' money problem task)

Hoover-Dempsey and Sandler's model identifies the generation of a closer fit between parental actions and school expectations as a precursor to greater pupil selfefficacy. The parents' actions contributed to this closer fit, providing a scaffold which enabled children to use the mathematical concepts they need to master in an enjoyable way. 


\section{Theme 2: Children enjoyed the homework}

Evidence on completion rates, responses to the self-efficacy questionnaire and comments relating to processes built into the pilot suggest that most children viewed the homework positively. Two particular factors were particularly important here: the impact of the homework changeover session and the role of the teacher.

Homework completion rates may indicate enjoyment, although they are clearly not necessarily evidence of enjoyment. The teachers kept a record of homework completion and, during the pilot, the average rate of return was between $70 \%$ and $80 \%$. This was a favourable rate when compared with previous homework. This may be indicative of enjoyment and / or an awareness of the 'specialness' of the situation. Certainly, comments made in the parent focus group suggested feelings of enjoyment, as they confirmed that the children were keen to complete the homework:

I feel like it was fun and unlike normal homework. I did quite a lot with mine therefore really liked doing it.

Great idea. It got them involved. It got them doing it.

It made it enjoyable. They engage more if it is something that is enjoyable

The possibility of different outcomes to tasks may have increased children's willingness to "have a go" although generally only one response was made. They liked having the freedom to choose their response:

I think it is good because we were not told to do it in one way we could do it in different ways and colour.

I liked it because you got to explore what you wanted to do.

I liked all the unique ways you chose to do the tasks.

There was variation within the class. The pupils in Group 3 had the lowest proportion with only $48 \%$ completion. The timing of the project may have influenced this. Late in the summer term, normal routines in school and at home tend to become 
disrupted. However, the question of non-completion could not be pursued in the focus groups because of the sensitivity of the issue. In addition, different tasks were met with varying degrees of enthusiasm by the children. The most popular appeared to link with children's current interests. For example, the co-ordinates task used a popular adventure construction-style video game. In this instance, the homework may have been more likely to stimulate children to show their solutions to parents. However, it was not feasible to develop enough tasks for all of the children's interests all of the time. A combination of tasks linked to interests or everyday use of mathematics was a more achievable strategy.

The self-efficacy questionnaire was completed during homework changeover sessions one, four (prior to stimulation of parental involvement), and at the end of the pilot. As explained earlier, children responded to attitudinal statements about mathematics using a four-point Likert-like scale. The mean scores derived from the raw data indicated that average self-efficacy levels started high in week 1, (with mean scores above 3.0 for each statement) and remained similar at week 4 and week 8 . Limitations of the sample and time frame, together with the lack of a control group meant data from the questionnaires could not be considered in the analysis. However, the consistently high scores, taken in the context of the focus group comments, suggest that the homework appears to have done no harm to pupils' self-efficacy. Furthermore, the questionnaire itself offers a viable tool for use in any future experimental study.

The homework changeover session in class was a new practice. It immediately raised the profile of homework. One child explained that "It's nice to see other people's work to see what they've done different and it can help you if you get stuck". Another pointed out that "it helps you learn more and it's not like just looking at other people's work". The children's homework scrapbooks were shared during the session and examples of different responses to the task shared. Children's comments recognised the difference in this form of homework:

It's not like normal homework; you have to stick things in. It's like crafty. 
It is like the work in school but like it's making it in fun different ways instead of just the teacher explaining it.

I really enjoyed it and it was different to have the big folder and do different ones each week.

We used to just have a piece of paper; it was white and now it is colourful

During the changeover sessions, children were encouraged to talk to each other about their homework. This form of peer review was not usually applied to homework. It allowed for a range of methods to be discussed, highlighting the fact that tasks could be completed in different ways. Many of the children took pride in their scrapbooks and were keen to share ideas. This was one of the covariates taken into account initially and may have contributed to the relatively high completion rate. The difficulty with using this process is when a child has not attempted the homework. This is where the role of the teacher is crucial. Teachers' pedagogical expertise allows them to include pupils without their homework, using peer review strategies.

Children were asked to explain how they felt about sharing their homework publicly (i.e. with their peers in class). Comments centred on enjoyment, new learning and concern:

\section{I enjoyed it.}

It was good I hope it can continue.

I feel quite happy.

If they didn't get the task I liked the way they improvised.

It helps you learn more about it and learn it is helpful and not like just looking at other people's work.

Sometimes felt a bit unsure as sometimes other people had done more than me.

I felt quite good but when I felt I didn't do too much or like I didn't do that good I didn't want to show mine. 
The final two comments above highlight the sensitivity of the homework changeover strategy and the key role played by the teacher to make it productive for all children. The commitment of both teachers accounted for much of the pilot's success. It is the teachers who facilitate the crucial changeover session using their pedagogic knowledge to keep all children involved. The pilot school had a record of effective mathematics teaching. However, like many schools, it faces the twin challenges of making the using and applying of mathematics as meaningful as possible, as well as developing parental involvement, which may be difficult for a range of social, cultural and economic reasons, the analysis of which is beyond the scope of this paper. As these challenges are common and familiar in many educational settings, it is hoped that the insights gained and issues raised in this project will be useful to those facing similar situations in settings elsewhere. The pilot ended with a celebration of the children's work, and the researchers distributed 'Party Bags', thus echoing the theme of the initial homework task. In addition, an informal, evaluative discussion with the two teachers who had been involved with the pilot took place at this stage. Their feedback has been included in the concluding remarks that follow.

\section{Conclusion}

Evaluation of the pilot suggests that the homework strategy does have sufficient promise to justify further research. Most children expressed enjoyment from the opportunity to share and celebrate their efforts, while many parents demonstrated a willingness to get involved. During the pilot, it became apparent that self-efficacy seemed strong for most children - and, while it is possible that the homework strategy may be able to protect or increase self-efficacy, this cannot, of course, be claimed here. However, it is pertinent here to reflect more widely on the thematic findings from the pilot, and their implications for practice.

In one respect, homework may be characterised as is simply another example of a school-initiated task that requires parental presence (Goodall, 2014, p. 134). An alternative view, though, is that it is an example of engaging parents in an effective form of involvement which has a number of potential benefits and which has little cost. The use of open-ended problem solving tasks embedded in everyday mathematics 
contributes to a child's ability to reason and apply their knowledge and skills. This fits, we suggest, with the rationale for what is sometimes termed "Maths Mastery": an approach to mathematics from high performing education systems such as Singapore, which has been capturing the attention of researchers and policy-makers. It is an approach which has been described as underpinning the current National Curriculum for England (NCETM, 2014). The mastery approach covers fewer topics in great depth. It prioritises problem solving skills over procedural knowledge in order to develop deep understanding or mastery of concepts (Jerrim and Vignoles, 2016, p. 31). Parental modelling, encouragement and reinforcement can help to provide a scaffold which enables children to explore the use of the mathematical concepts they need to master, in an enjoyable way.

\section{Implications for practice}

Inevitably, finding the time to produce the homework tasks is challenging initially. Nonetheless, once a bank of homework activities has been developed, it should involve no additional work. In terms of the school day, it may appear difficult to identify the 30 minutes for the homework changeover session within a school timetable. However, the experience during this pilot study suggests that this process is a valuable opportunity to celebrate effort and use peer assessment. Evidence suggests that peer assessment of children's responses to the tasks will generate useful feedback, help them to become more self-regulating and lead them to more effective learning strategies in future (Topping, 2003). Parents could be invited to attend a homework changeover session as a 'hook' to show how their involvement has a positive effect and to model feedback and questioning strategies. This would show children that their parents and teachers both valued their efforts. If the child sees that the homework is valued at home, as well as in school, they are more likely to see it as meaningful. One child pointed out another benefit. He felt the homework was good because "it helps you to spend more time with your family".

Discussions with the participating teachers identified several organisational changes that might improve effectiveness. First, it is recommended that the pilot should launch at the start of the school year, in order to capture the energy and optimism of children and parents. This would allow for a longer pilot and a more meaningful 
measure of self-efficacy. Second, we would suggest that the launch of the project should be as informal as possible and allow for greater lead-in time to maximise face-to-face contact with parents. Third, a website should be developed to serve as a resource for sharing ideas and information on supporting children's learning in mathematics. Fourth, different models of delivery could be used, depending on school context and priorities. For example, the homework could be given to the whole school for a half term, or it could be given fortnightly, alternating with other subjects such as local history or art and culture. Fifth, a pack of homework tasks should be disseminated to all teachers, to encourage the embedding of the practice.

Thinking about the purposes of homework should be part of a wider reflection on our expectations and understanding of the respective roles of parents and teachers. Achieving the type of parental involvement at the top of the Hoover-Dempsey and Sandler hierarchy is not easy. However, since homework is seen as a "normal" school activity, it is, with think, a logical strategy to use. The findings of our thematic analysis indicate that, in this setting at least, it it was well-received and perceived to be manageable rather than burdensome. The next step should be to run a larger and longer version of the pilot, with a view to designing a larger study to investigate its effectiveness.

\section{References}

Bailey, L. (2006). Interactive Homework: A Tool for Fostering Parent-Child Interactions and Improving Learning Outcomes for At-risk Young Children. Early Childhood Education Journal, 34:2, 155-167.

Bandura A. (1997). Self-Efficacy: The Exercise of Control. New York: Freeman.

Bassey, M. (1999). Case Study Research in Educational Settings. Buckingham: Open University Press.

Bassey, M. (2001). A Solution to the Problem of Generalisation in Educational Research: Fuzzy prediction. Oxford Review of Education, 27:1, 5-22.

Benbenutty, H. (2011). The First Word: Homework's Theory, Research and Practice. Journal of Advanced Academics, 22:2, 185- 192.

BERA (2011) Ethical Guidelines for Educational Research. London: British Educational Research Association. 
Bernie, J. \& Lall, M. (2008). Building bridges between home and school mathematics: A review of the Ocean Mathematics Project. Institute of Education: University of London.

Braun, V. \& Clarke, V. (2006). Using thematic analysis in psychology. Qualitative Research in Psychology, 3:2, 77-101.

Cooper, H., Robinson, J. C., \& Patall, E. A. (2006). Does Homework Improve Academic Achievement? A Synthesis of Research, 1987-2003. Review of Educational Research, 76:1, 1-62.

Corno, L., Fan, X., \& Chen, M. (2001). Parental Involvement and Students' Academic Achievement: A Meta-Analysis. Educational Psychology Review, 13:1, 1-22.

Department for Children Schools and Families. (2007). Homework Guidance for Primary and Secondary Schools. London: DCFS.

Department for Education. (2015). Pre-school and early home learning effects on Alevel outcomes Effective Pre-School, Primary \& Secondary Education Project (EPPSE) Research report. London: DFE.

Eccles, J.S., \& Wigfield, A. (2002). Motivational beliefs, values, and goals. Annual Review of Psychology, 53, 109-32.

Eden, C., Heine, A., \& Jacobs, A. M. (2013). Mathematics Anxiety and Its Development in the Course of Formal Schooling - A Review. Psychology, 4: 6A2, 2735.

Epstein, J., \& Van Voorhis, F. (2012). The changing debate from assigning homework to designing homework. Chp. 24. In Sebastian Suggate and Elaine Reese (Eds.) Contemporary Debates in Childhood Education and Development (pp. 263-274). London: Routledge.

Farrell, A., \& Danby, S. (2013). How does homework 'work' for young children? Children's accounts of homework in their everyday lives. British Journal of Sociology of Education, 36:2, 250-269.

Greene, J., Caracelli, J. \& Graham, W. (1989). Towards a Conceptual Framework for a Mixed-Method Evaluation Design. Educational Evaluation and Policy Analysis, 11:3, 255-274.

Greene, J. (2006). Toward a Methodology of Mixed Method Social Enquiry. Research in the Schools, 13:1, 93-98. 
Greene, J. (2015). The Emergence of Mixing Methods in the Field of Evaluation. Qualitative Health Research, 25:6, 746-750.

GOV.UK (2016). Summer-2015-gcse-results-a-brief-explanation (https://www.gov.uk/government/news/summer-2015-gcse-results-a-brief-explanation, last accessed January 18 2016).

Harris, A. \& Goodall, J. (2008). Do parents know they matter? Engaging all parents in learning. Educational Research, 50:3, 277-289.

Hattie, J. (2009). Visible Learning: A Synthesis of Over 800 Meta-Analyses Relating to Achievement. London: Routledge.

Haylock, D. (2007). Mathematics explained for primary teachers (3rd Ed.). Thousand Oaks, CA: Sage Publications.

Hoover-Dempsey, K.V., \& Sandler H.M. (1995). Parental involvement in children's education: Why does it make a difference? Teachers College Records, 97, 310-331.

Hoover-Dempsey, K.V., \& Sandler, H.M. (2005). Final Performance Report for OERI Grant \# R305T010673: The Social Context of Parental Involvement: A Path to Enhanced Achievement. Presented to Project Monitor, Institute of Education Sciences, U.S. Department of Education.

Jerrim, J., \& Vignoles, A. (2016). The link between East Asian 'mastery' teaching methods and English children's mathematics skills. Economics of Education Review, 50, $29-44$.

Kaiser, A. P., \& Hancock, T. B. (2003). Teaching Parents New Skills to Support Their Young Children's Development. Infants \& Young Children: An Interdisciplinary Journal of Early Childhood Intervention, 16:1, 9-21.

Kraft, M.A. \& Rogers, T. (2015). The underutilized potential of teacher-to-parent communication: Evidence from a field experiment. Economics of Education Review, 47, $49-63$.

Landers, M. (2013). Towards a theory of mathematics homework as a social practice. Educational Studies in Mathematics, 84:3, 371-391.

Linnenbrink, E. A., \& Pintrich, P. R. (2002). Motivation as an Enabler for Academic Success. School Psychology Review, 31:3, 313-327.

Linsell, C., Cavanagh, M., \& Tahir, S. (2013). Using meaningful contexts to promote understanding of; pronumerals. Australian Mathematics Teacher, 69:1, 33-40. 
Maloney, E., Schaeffer, M., \& Beilock, S. (2013). Mathematics anxiety and stereotype threat: shared mechanisms, negative consequences and promising interventions. Research in Mathematics Education, 15, 2, 115-128.

Mcnamara, O., Hustler, D., Stronach, I., Rodrigo, M., Beresford, E., \& Botcherby, S. (2000). Room to manoeuvre: Mobilising the "active partner" in home-school relations. British Educational Research Journal, 26:4, 473-489.

Merttens, R. \& Vass, J. (Eds.) (1993). Partnerships in maths: Parents and schools the IMPACT project. London: The Falmer Press.

National Centre for Excellence in the Teaching of Mathematics. (2014). Mastery approaches to mathematics and the new national curriculum.

(https://www.ncetm.org.uk/public/files/19990433/Developing_mastery_in_mathematics _october_2014.pdf last accessed 21 March, 2016).

Nicol, C., \& Crespo, S. (2005). Exploring mathematics in imaginative places: rethinking what counts as meaningful context for learning mathematics. School Science and Mathematics, 105:5, 240-251.

OECD.ORG (2012) PISA Results. (OECD.ORG/pisa/keyfindings/PISA-2012-resultsUK.pdf last accessed January 18 2016).

Ofsted. (2008). Mathematics; understanding the score. (Report No. 070063). Ofsted. Ofsted. (2012). Mathematics: Made to Measure. (Report No.110159). Ofsted.

Ofsted. (2015). School inspection handbook for inspecting schools in England under section 5 of the Education Act 2005. Manchester: Ofsted.

Onslow, B. (1992). Improving the attitude of students and parents through family involvement in mathematics. Mathematics Education Research Journal, 4:3, 24-31.

O’sullivan, R.H., Chen, Yung-Chi. \& Fish, M.C. (2014). Parental Mathematics

Homework Involvement of Low Income Families with Middle School Students. School Community Journal, 24: 2, 165-187.

Patall, E. A., Cooper, H., \& Robinson, J. (2008). Parent Involvement in Homework: A Research Synthesis. Review of Educational Research, 78:4, 1039-1101.

Pintrich, P. R., \& De Groot E. (1990). Motivational and self-regulated learning components of classroom academic performance. Journal of Educational Psychology, 82:1, 33-40.

Sheldon, S \& J. Epstein, J. (2005). Involvement Counts: Family and Community Partnerships and Mathematics Achievement. The Journal of Educational Research, $98: 4,196-206$. 
Silinskas G, Kiuru N, Aunola K, Lerkkanen M, Nurmi J. (2015). The Developmental Dynamics of Children's Academic Performance and Mothers' Homework-Related Affect and Practices. Developmental Psychology, 51:4, 419-433.

Stake, R. (1995). The Art of Case Study Research. Thousand Oaks, Calif: Sage.

Topping, K. J. (2013). Peers as a source of formative and summative assessment. In J. H. McMillan (Ed.), The SAGE handbook of research on classroom assessment (p. 395 412). Thousand Oaks, CA: Sage.

Treffers, A., \& Beishuizen, M. (1999). Realistic mathematics education in the Netherlands. In I. Thompson (Ed.) Issues in Teaching Numeracy in Primary Schools. Buckingham: Open University Press.

Van Voorhis, F. L. (2009). Does Family Involvement in Homework Make a Difference? Investigating the Longitudinal Effects of Math and Language Arts Interventions, Chp. 10. In Rollande Deslandes (Ed.) International Perspectives on Student Outcomes and Homework. Family-school-community partnerships. London and New York: Routledge. Van Voorhis, F. L. (2011). Adding Families to the Homework Equation: A Longitudinal Study of Mathematics Achievement. Education and Urban Society, 43:3, 313-338.

Walker J.M.T., Wilkins, A.S., Dallaire, J.R., Sandler, H.M., \& Hoover-Dempsey, K.V. (2005). Parental involvement: Model revision through scale development. The Elementary School Journal, 106; 2, 85-105.

Wenger, E. (1998). Communities of practice: Learning, meaning, and identity.

Cambridge: Cambridge University Press.

Wilder, S. (2014). Effects of parental involvement on academic achievement: a meta-synthesis. Educational Review, 66:3, 377-397. 
ER_resub 0183 accepted version 2617

Page 31 of $34 \quad$ restricted 
ER_resub 0183 accepted version 2617

Page 32 of $34 \quad$ restricted 


\section{Level 5}

\begin{tabular}{|l|}
\hline Student Achievement \\
\hline
\end{tabular}

Level 4

\begin{tabular}{|c|c|c|c|}
\hline \multicolumn{4}{|c|}{ Student Attributes Conducive to Achievement } \\
\hline Academic Self & Intrinsic Motivation & Self-Regulatory & Social Self \\
Efficacy & To Learn & Strategy to Use & Efficacy Teachers \\
\hline
\end{tabular}

Level 3

\begin{tabular}{|c|c|c|c|}
\hline \multicolumn{3}{|c|}{ Mediated by Child Perception of Parent Mechanisms } \\
\hline Encouragement & Modelling & Reinforcement & Instruction \\
\hline
\end{tabular}

Level 2

\begin{tabular}{|l|c|c|c|}
\hline \multicolumn{3}{|c|}{ Parent Mechanisms of Involvement } \\
\hline Encouragement & Modelling & Reinforcement & Instruction \\
\hline
\end{tabular}

\begin{tabular}{|c|c|c|c|}
\hline \multicolumn{3}{|c|}{ Parent Involvement Forms } \\
\hline Values & Home & School & School \\
Goals & Involvement & Curriculum & Involvement \\
etc. & & & \\
\hline
\end{tabular}

Level 1

\begin{tabular}{|c|c|c|c|c|c|c|c|}
\hline \multicolumn{2}{|c|}{ Personal Motivation } & \multicolumn{3}{|c|}{ Invitations } & \multicolumn{3}{c|}{ Life Context } \\
\hline Parental & Parental & General & Specific & Specific & Knowledge & Time & Family \\
Role & Efficacy & School & School & Child & and & and & Culture \\
Construction & & Invitation & Invitation & Invitation & Skills & Energy & \\
\hline
\end{tabular}

Figure 1. The Hoover-Dempsey \& Sandler model of parental involvement. Adapted from Hoover-Dempsey \& Sandler, 1997; 2005. Reprinted with permission from Joan Walker on behalf of the Family School Partnership Lab, Vanderbilt University. 
ER_resub 0183 accepted version 2617

Page 34 of $34 \quad$ restricted 